\title{
Building the COVID-19 Collaborative Emergency Network: a case study of COVID-19 outbreak in Hubei Province, China
}

\author{
Jie Liu', ${ }^{1,2}$ Jingyu Hao ${ }^{1}$ - Zhenwu Shi ${ }^{1}$ - Helen X. H. Bao ${ }^{2}$
}

Received: 26 July 2020 / Accepted: 12 October 2020 / Published online: 17 October 2020

(c) Springer Nature B.V. 2020

\begin{abstract}
The purpose of this study is to uncover and optimize the structure and performance of the collaborative network that emerged in response to COVID-19 in Hubei Province, China. This study reconstructed the Hubei Public Health Emergency Response Network as the actual collaborative network and built COVID-19 Collaborative Emergency Network as a planned task-oriented collaborative network. Based on the data sets of the inter-organizational collaboration collected from the content analysis, this study explored the core tasks of the participating actors and their relationships during the COVID-19 emergency response, and built six sub-networks to accomplish six core tasks. Network analysis was used with the Pajek software to compare the structural characteristics and performance of the planned network with the actual one and six sub-networks, and identified the central actors, key bridges, and brokers in networks and sub-networks separately. Findings suggested that COVID-19 Collaborative Emergency Network had a more tightly, central, and connective structure than Hubei Public Health Emergency Response Network, because it had more participating actors (i.e., databases and AI systems), more powerful and strong collaborative relationships with research institutions and non-profit organizations. With practical-based recommendations for inter-organizational collaboration, this study concluded that COVID-19 Collaborative Emergency Network could significantly enhance the local capacity of Hubei Province for emergency collaboration, which provided insights for building and optimizing COVID-19 collaborative networks in other provinces of China, even other countries.
\end{abstract}

Keywords Collaborative Emergency Network · COVID-19 outbreak · Network analysis

\section{Introduction}

The coronavirus (COVID-19), as an etiological agent and human-to-human transmission of the virus (SARS-COV-2), is affecting 216 countries and territories around the world. It has been labeled as a pandemic by the World Health Organization (WHO). As of 08:00

Zhenwu Shi

shizhenwu@126.com

School of Civil Engineering, Northeast Forestry University, 26 Hexing Road, Harbin, China

2 Department of Land Economy, University of Cambridge, 19 Silver Street, Cambridge, UK 
am(GMT +8) on 30th August 2020, 24,854,140 were confirmed positive for COVID-19, and 838,924 have died (World Health Organization 2020). In China, COVID-19 broke out from Wuhan in December 2019 and spread rapidly. To control and prevent further dispersal of this pandemic disease, the central government of China imposed a lockdown in Wuhan. It raised its national public health emergency response to the highest state of emergency (Level One-extremely serious incident) on January 23, 2020. During the lockdown period, many non-pharmaceutical interventions were implemented in Wuhan timely and expertly. Such interventions cannot be tackled by one public organization or one policy sector alone, but rather need collaborated actions from different organizations in multiple policy sectors. This collaboration is reflected in practice in the form of a collaborative network (Rhodes 1996; Bryson et al. 2006). It is a dynamic set of integrative working arrangements to foster collaboration among local, national, and international governments, policy sectors, research institutions, and non-governmental organizations (NGOs). The collaborative network is a comparatively less rigidity, more flexible, and non-hierarchical, targeted at loose relationships for improving emergency management (Comfort et al. 2012; Molenveld et al. 2019). Emergency management organizations build and sustain the collaborative network to effectively mobilize efforts in response to the multiple events of disasters by sharing information, financial resources, human capital, and expertise (Kapucu and Garayev 2012).

In the field of emergency management, it is a consensus that emergency response is best understood as a collaborative network phenomenon (Waugh and Streib 2006). A collaborative network is designed as a new governance structure that a variety of actors collaborate to achieve a desirable unified goal (Hill and Lynn 2009). In disaster response, the collaborative network is believed to be more effective than a market or hierarchy when requires an adaptive and flexible approach due to inconsistent information or uncertain conditions existing, or when the knowledge and resources are needed to address the issue spans boundaries (Provan and Lemaire 2012). So research on the collaborative network has focused on investigating and exploring properties and processes of such networks, its development, and evolution, governance, aggregate outcomes, and effectiveness (Provan et al. 2007). Some researches focused on the structural characteristics of the collaborative network (Turrini et al. 2010), for example type and intensity of external control (Provan and Milward 1995), integration mechanisms and tools (Jennings and Ewalt 1998), and the inner stability of the collaborative network (Ferlie and Pettigrew 1996). Through the "network analytical" approach, scholars have contributed notably to the description and explanation of these structural characteristics using such concepts as density, centrality, and structural holes (Wasserman and Faust 1994). The units of observation are a set of objects called nodes, positions, or actors, and a set of present or absent relations among these objects referred to as edges, ties, or links (Knoke 1990). Some researches focused on describing and explaining inter-sector, intergovernmental and inter-organizational interactions (e.g., strong dyadic relationships and reciprocated positive ties) by the node-level analysis and whole-network-level analysis, and understanding the performance and governance of these sectors, government, and organizations in the collaborative network (Kapucu and Demiroz 2011), then to identify its power or role in emergency management (Koliba et al. 2010), such as bridgers (Wilson and MacDonald 2018), translators, and brokers. Compared with analyzing the formal interactions among multiply sectors, governments, and organizations (Choi and Brower 2006), some researchers have examined the impact of their informal social bonding relationships on the performance of the collaborative network during disaster response (Isett et al. 2011). These researches claimed that a higher level of consensus, trust, commitment, mutual dependence, and thickness of communication contribute 
to collaboration (Bouckaert et al. 2010). Most of the network analysis methods and tools used in the literature above have been descriptive (Huxham and Vangen 2005). Recently, a growing literature has begun to use more advanced statistical analysis techniques to integrate qualitative with quantitative studies, conducted large-N network analysis and comparative network analysis of the collaborative networks, particularly those concerned with disasters (Kapucu 2006).

While most of the previous research focused on building and analyzing the collaborative network in response to natural or human-made disasters rather than a public health crisis (Feiock et al. 2012; Comfort 2007). Particularly when responding to a pandemic, in addition to emergency relief, the outcome goal of the collaborative network is to prevent and control the spread of infectious diseases. Therefore, this different goal needs a different structural network, different participating actors, and different collaborative practices that are explored by network analysis. COVID-19, as one of the worst public health crisis in a generation, provides an excellent opportunity to test this research question. The primary objective of this study is to investigate the distinct pattern of the actual collaborative network in the case of the COVID-19 outbreak in Hubei Province, China, then improve the inter-organizational collaboration output, and enhance the network performance and effectiveness by creating a planned collaborative network. First, this study examined the structural characteristics of the Hubei Public Health Emergency Response Network, by answering three empirical research questions: who were the participating actors? What were the specific tasks of these actors? How did the interactions among these actors? Second, based on identifying six core tasks during COVID-19 response operations, six subnetworks were explored with different participating actors and different relationships to yield varying effects. Then, COVID-19 Collaborative Emergency Network was created as a planned joint network. The network analysis was used to answer the question: Did this newly planned network optimize the existing one? What aspects of structure and relationships were associated with improved performance and capacity of the network? What types of actors played the central roles, or served as key bridges or brokers in two networks and six sub-networks, separately? This study provided an insight into the task-oriented collaborative network in response to COVID-19. It highlighted the critical roles of databases, AI systems, local governments, non-profit organizations, research institutions, and their stronger relationships with policymakers in shaping this collaborative network.

\section{Data and method}

\subsection{Data collection}

As for identifying the collaborative relationships among actors in response to the COVID-19 outbreak, the content analysis was conducted on news reports, government documents, and situation reports. These reports and documents included daily updates of COVID-19 in Hubei Province, which were from Hubei's press briefing on the latest COVID-19 control efforts, the notices published by Hubei COVID-19 Prevention and Control Headquarter, Hubei Daily, Changjiang Daily, Wuhan Night, Sanxia Night, Chutian Metropolis Daily, etc. Data collection was also performed by manual inspection and information retrieval from all source web sites. Materials were collected by searching online sources of documents, including commercial search engines (e.g., Baidu and Google), National and Provincial web sites (Hubei provincial government, Health 
Commission of Hubei Province), press releases (Xinhua Net, People's Daily Online, China News), and a census of potential sources (Sina Weibo, Tencent Wechat). This collecting process was conducted daily from January 23, 2020, to April 8, 2020. Through about COVID-19 response efforts handled by governmental, local, and international agencies in Hubei Province, all informational material was gathered, all participating actors were numbered and catalogued, all response efforts were recorded, and all collaborative relationships were noted. These documents mentioned above were all carefully reviewed to detail the inter-organizational collaboration in response to COVID-19 in Hubei Province, China. Then, all the content analysis was compiled into one master document for building Hubei Public Health Emergency Response Network.

\subsection{The framework of Hubei Public Health Emergency Response Network}

For implementing the non-pharmaceutical interventions quickly, collaboratively, and effectively, the Government of Hubei Province built Hubei Public Health Emergency Response Network on January 20, 2020, with other participating actors (e.g., governments, non-governmental organizations (NGOs), research institutions, and private organizations). The Hubei Public Health Emergency Response Network was built based on the Hubei Public Health Emergency Response Plan, which was announced and published by the Government of Hubei Province on April 22, 2010. The framework of the Hubei Public Health Emergency Response Network is shown in Fig. 1. In this network, Hubei COVID-19 Prevention and Control Headquarter located in a core position and connected with most of the participating actors. It was also the leader of all local participating actors, who organized and commanded these actors to achieve the public health goal of ending the COVID-19 outbreak in Hubei Province. And there was a strong collaborative relationship among Leading Group of the CPC Central Committee for COVID-19 Prevent and Control, State Council of the PRC, Hubei COVID-19 Prevention and Control Headquarter, and the Government of Hubei Province.

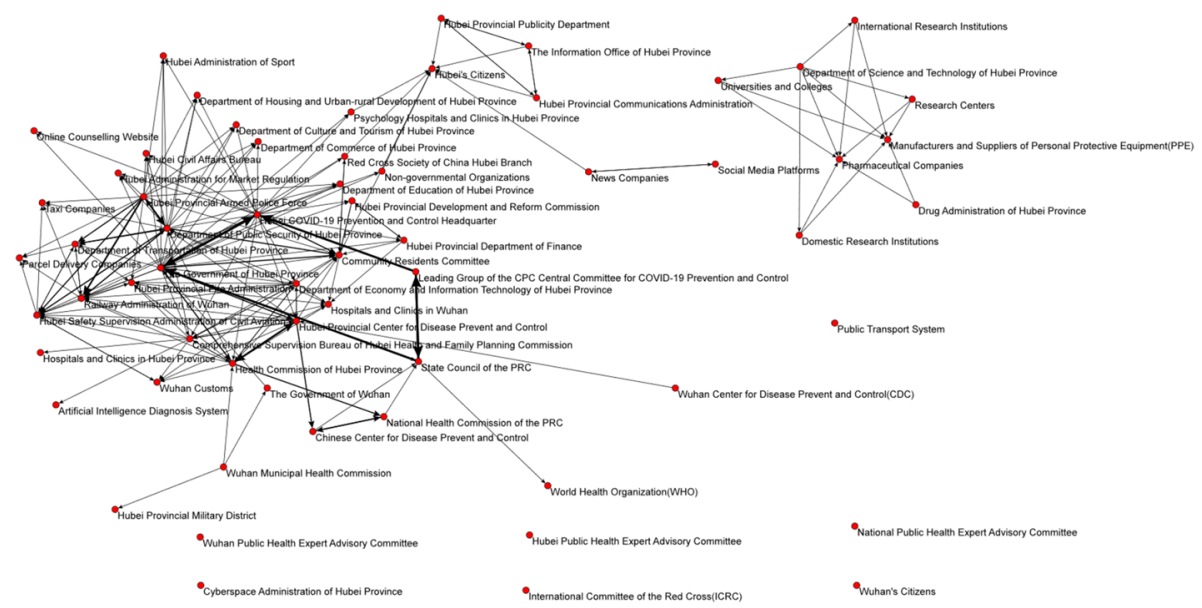

Fig. 1 The framework of Hubei Public Health Emergency Response Network 


\subsection{The framework of COVID-19 Collaborative Emergency Network}

The Hubei Public Health Emergency Response Network is likely to be much more formalized, emphasizing its stable and bureaucratic structure. In this network, Hubei COVID19 Prevention and Control Headquarter is the lead actor responsible for organizing and commanding all local participating actors to implement the response efforts in Hubei Province. It may hinder the collaborative effectiveness of the participating actors in the response phase. In this phase, the number of actors, actors' position, as well as their patterns of interaction with others change over time, depending on the tasks carried out by actors (Noori et al. 2016). So some participating actors may become centralized among some key coordinators in charge of a specific task, and at the same time, these same actors can reduce or even break their current relationships and develop ties to others, as the task changes (Topper and Carley 1999). These highly flexible and adaptable relationships allow the participating actors to respond quickly and collaborate easily, which is ideal for forming collaborative networks. So focusing on "viewing the tasks as the center point," this study built COVID-19 Collaborative Emergency Network based on six core tasks and further categorized it into six sub-networks: (1) monitoring, early warning, and reporting the COVID-19, (2) implementing COVID-19 prevention and control measures, (3) treating COVID-19 patients and researching the COVID-19, (4) allocating and transporting the funding and medical supplies, (5) releasing and publishing the information on COVID-19, (6) implementing the training measures and psychological interventions to the public. The sub-network structure predicted different coronavirus-related tasks carried out by different participating actors. Their roles can change to form different patterns of interaction, and their multiplex interaction can vary to form multiple collaborative activities (Robinson et al. 2013).

\subsection{Network analysis of COVID-19 Collaborative Emergency Network}

In the emergency management field, several studies have shown that network analysis is practical in understanding how the collaborative network connects actors across various boundaries when circumstances - and the networks themselves - shift and transform to varying needs and structures following a rapid disaster-induced shock. Therefore, in this paper, the structured data from content analysis were used as an input to network analysis. Moreover, the network analysis was performed with the Pajek software to build COVID19 Collaborative Emergency Network and its six sub-networks. It assessed the collaborative relationships among the participating actors and measured the vital structural features by several indicators: (1) density measures the level of connectivity and linkage among the participating actors operating within a network. The higher the density of a network, the higher the connectivity in terms of communication flow and information exchange. A low density depicts a sparse network that contains isolates and restricts communication, information, and resource flow. (2) Two network centralities were calculated as sources of advantage: degree and betweenness. Degree centrality measures the total connections an actor has in a collaborative network, which can be used to identify actors with an extensive collaborative activity. By calculating the number of ties an actor possesses, it determines how well-connected the actor is in a collaborative network. Actors with more ties hold more influential positions because they potentially have access to more actors, knowledge, information, ideas, etc. Betweenness centrality measures how important an actor is to the 
shortest paths through a collaborative network, which indicates the importance of an actor in connecting with others or how central it is in a collaborative network. So an actor with a higher score in a network is particularly likely to be in a vital position to maintain contact between actors not otherwise able to share information or resources. (3) Structural hole analysis is used to identify the structural holes and brokerage roles played by different actors. It examines actors who would be much less connected, or who holds a more prominent brokerage position in connecting with other actors. Furthermore, a higher score means that the actor has a higher opportunity to be a structural hole. The other actor in connecting with it has a higher opportunity to be a broker, who is viewed as an attractive relationship partner.

\section{Results}

An overall visual representation of the COVID-19 Collaborative Emergency Network is depicted in Fig. 2, which shows the inter-organizational collaboration among the 72 actors in response and relief efforts to COVID-19 in Hubei Province. COVID-19 Collaborative Emergency Network is constructed not only from collaborative relationships (represented by a double-headed arrow) but also from reporting or governance relationships (represented by a single-headed arrow). Ties on black color indicate the traditional collaborative, reporting, or governance relationships among actors in Hubei Public Health Emergency Response Network, while ties on orange color indicate the new collaborative, reporting, or governance relationships that we add to strengthen the collaborative capacities of actors. Moreover, the width of the displayed ties indicates the collaboration strength among diverse actors. In this network, some traditional relationships have been strengthened, such as the relationships among Chinese Center for Disease Prevent and Control, Health Commission of Hubei Province, Hubei Provincial Centre for Disease Prevent and Control, and National Health Commission of the PRC, and also the relationships among Hubei Provincial Armed Police Force, Railway Administration of Wuhan, Department of Transportation

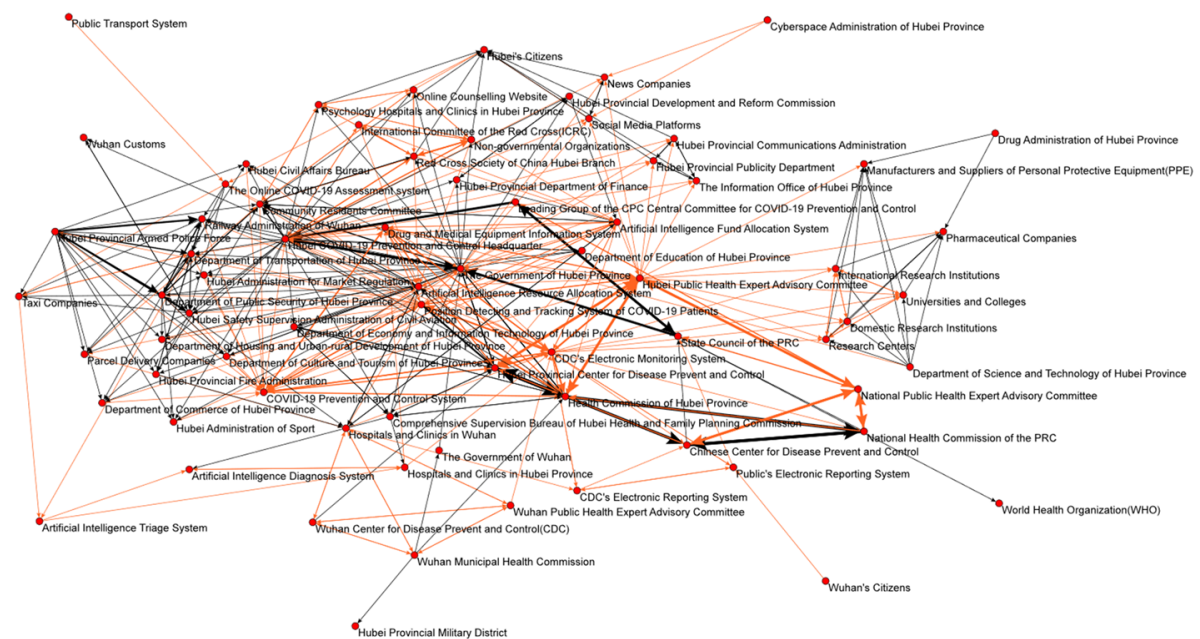

Fig. 2 The framework of COVID-19 Collaborative Emergency Network 
of Hubei Province, Department of Public Security of Hubei Province, and Hubei Safety Supervision Administration of Civil Aviation. There are some newly added firmly connections among Hubei Public Health Expert Advisory Committee, National Public Health Expert Advisory Committee, National Health Commission of the PRC, Chinese Center for Disease Prevent and Control, Health Commission of Hubei Province, Hubei Provincial Centre for Disease Prevent and Control.

\subsection{Sub-network one: monitoring, early warning, and reporting the COVID-19}

During the initial stages of the COVID-19 outbreak, the core task of the COVID-19 Collaborative Emergency Network is to quickly and effectively report the COVID-19 pandemic. The sub-network one (shown in Fig. 3) consists of three parts: the first part for monitoring and early warning the COVID-19 pandemic, the second part for storing data, and the third part for reporting the COVID-19 pandemic. In the first part, compared with the existing early warning systems for infectious diseases, we add the actor of the Wuhan Public Health Expert Advisory Committee, which could provide a detailed virological analysis of hospitalized patients with COVID-19 since this virus was discovered. We also add the inter-relationships between the actors to improve the data sharing. In this second part, there are three databases. Based on the data relating to COVID-19 patients in hospitals and clinics, we add the CDC's Electronic Monitoring System to summarize the transmission and clinical characteristics of COVID-19. The CDC's Electronic Reporting System connects all Health Commissions, centers for Disease Prevent and Control (CDC), hospitals, and clinics in the country. Any actor in this system can share the latest data and analysis on COVID-19 with others and directly report it to the National Health Commission of the PRC and the Chinese Center for Disease Control and Prevention. These data and analysis include the number of daily new confirmed cases and deaths, the number of COVID-19 cases with no symptoms, mild, moderate or severe symptoms, the age, gender, and geographical distribution of COVID-19 cases. This system helps the National Health Commission understand the new transmission dynamics of the infection in Wuhan timely and accurately. We also add the Public's Electronic Reporting System in the database, which is used by Wuhan's citizens to report the local data regarding COVID-19 cases to the central government. This

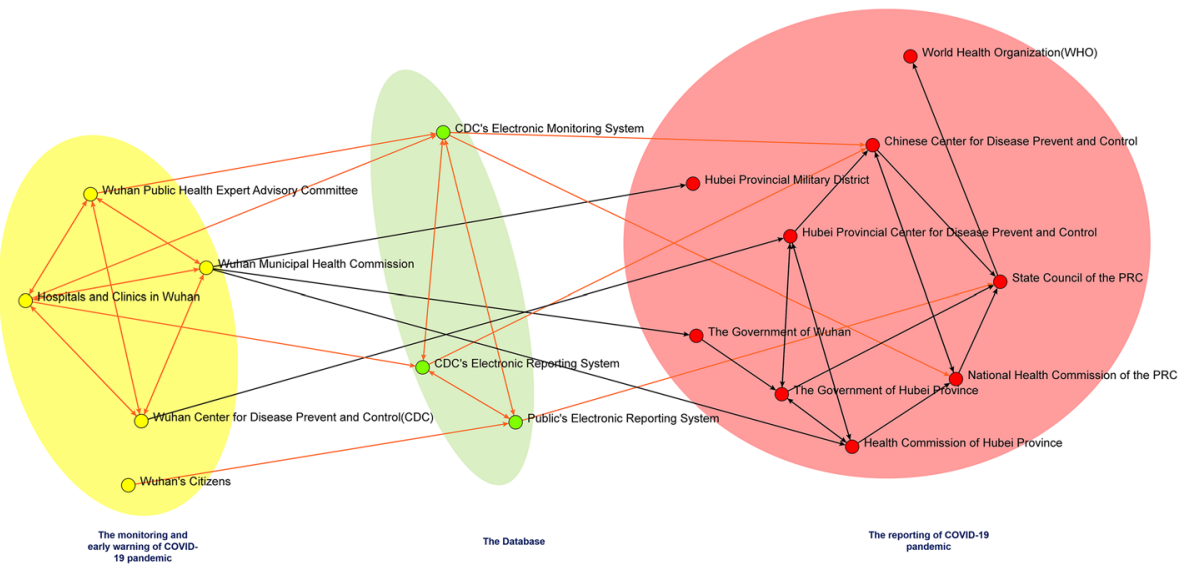

Fig. 3 The framework of sub-network one 
system helps the central government grasp the latest epidemic situation of the COVID-19 in Wuhan and prevent local governments from covering up new COVID-19 cases. In the third part, the formalized bureaucratic structure between the actors decides the reporting process of COVID-19, which is from the local governments and institutions in Wuhan to Hubei Province and further to the country.

\subsection{Sub-network two: implementing COVID-19 prevention and control measures}

In the initial response to the COVID-19 outbreak, a key goal of public health officials is to avoid a significant spike in infections in a short period in favor of a slower growth that flattens the curve. So public health experts and government officials have repeatedly referenced the importance of effective prevention and control measures. These measures can slow the spread of COVID-19 and keep the number infected at any one time at a manageable level, which ensures healthcare systems do not exceed capacity. Sub-network two (shown in Fig. 4) is built to represent the collaborative relationships between public health experts and government officials to determine and implement COVID-19 prevention and control measures. This sub-network consists of four parts: the first part for identifying COVID-19 patients and their close contacts, the second part for suggesting COVID-19 prevention and control measures, the third part for determining COVID-19 prevention and control measures, and the fourth part for implementing COVID-19 prevention and control measures. In the first part, we add two databases to identify and trace the COVID-19 patients and their close contacts timely and accurately. Based on the big data from internet companies and mobile operators, CDC's Electronic Monitoring System is added to identify the free source of infection (e.g., confirmed cases) quickly, including their locations and activity areas. This system helps public health officials determine the transmission route of COVID-19 and the source of COVID-19 outbreak in a particular area. Position Detecting and Tracing System of COVID-19 patients are added to search and trace the suspected cases and close contacts. By describing and deducing the transmission route of COVID-19, this system helps public health officials find potential close contacts with new COVID-19 patients accurately. COVID-19 Prevention and Control System collects and shares the real-time data of the prevention and control measures implemented in Hubei

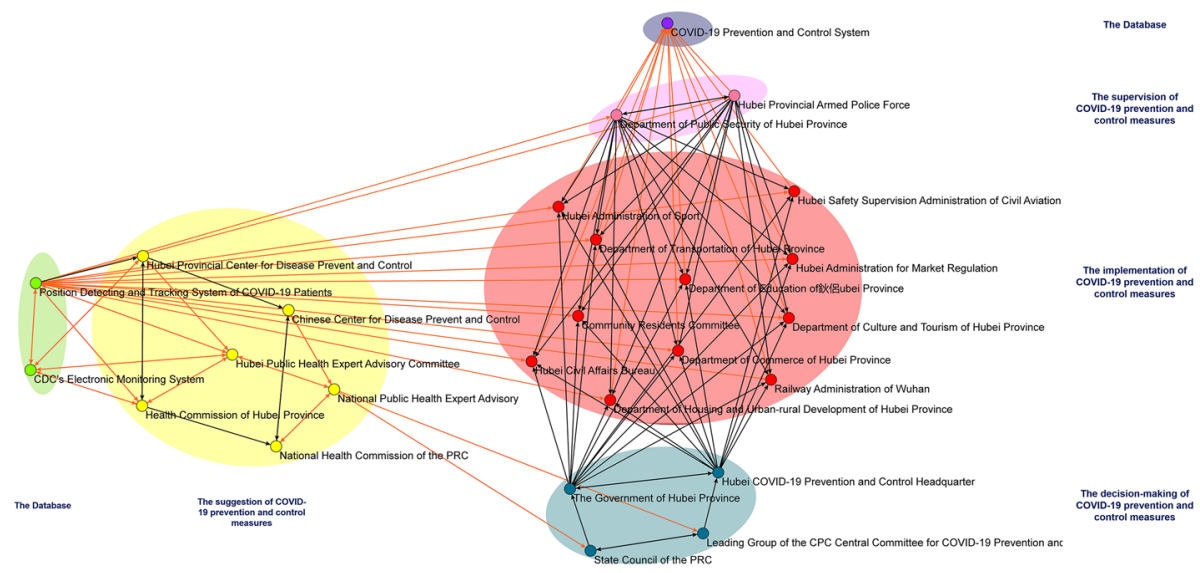

Fig. 4 The framework of sub-network two 
Province. All of the local government agencies in Hubei Province create tight interconnections to strengthen case-finding, isolate COVID-19 cases, and quarantine contacts, which is essential to stop chains of COVID-19 transmission and prevent new ones from appearing. In the second and third parts, before the COVID-19 prevention and control measures determined by the government officials, we add the neutral and diversified expert groups to provide scientific and reasonable suggestions for government officials. Due to their professional knowledge and first-hand working experience from frontline doctors, these scientific suggestions, which are the feedback about evidence summaries, support the government officials to optimize prevention and control measures rapidly. In the fourth part, the government officials implement different prevention and control measures in different combinations and at varying times in the local evolution of the COVID-19 pandemic, according to their tasks. All measures should be accompanied by bright, trust, and mutual relationships between the government officials through collaboration and joint decision-making processes and without exerting power- or hierarchy-related behaviors. So we add a lot of collaborative relationships in the fourth part. The more the connections among the government officials are, the better the sub-network effectiveness is. These collaborative relationships likely help the government officials to form more in-depth and more trust-based relationships with one another, as well as focus them on everyday tasks.

\subsection{Sub-network three: treating COVID-19 patients and researching the COVID-19}

Treating COVID-19 patients and researching the COVID-19 pandemic is at the heart of COVID-19 response. Effective treatment controls the rush of patients with COVID-19, and research has been reassigned to provide the best available knowledge on treating the COVID-19 infection. But in Hubei Public Health Emergency Response Network, the treating and researching processes are mutually independent, which limit the cross-sector collaboration between hospitals and research centers. For implementing the cross-sector collaboration, the sub-network three (shown in Fig. 5) consists of four parts: the first part for identifying the COVID-19 patients, the second part for transporting the COVID-19 patients, the third part for treating the COVID-19 patients, the fourth part for researching and producing the new drugs and medical equipments. In the initial stage of the COVID-19

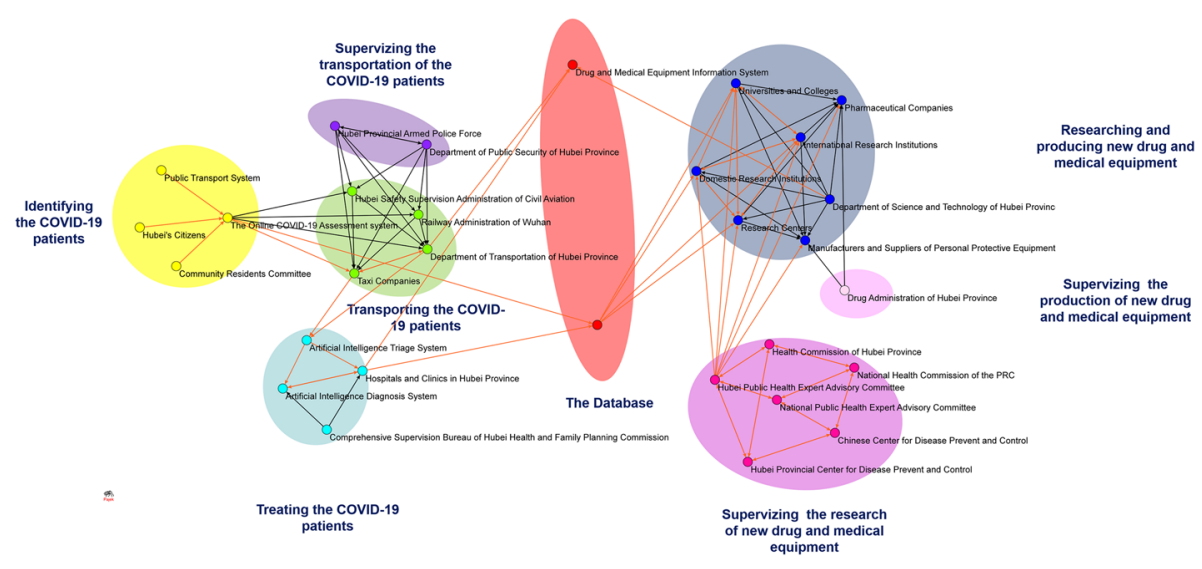

Fig. 5 The framework of sub-network three 
outbreak, many people were waiting for testing and diagnosing in Hubei's hospitals. This traditional diagnostic system accelerates the spread of COVID-19 pandemic under the situation of insufficient personal protective equipment (PPE) for protecting healthcare workers, and lacking strict policy for isolating suspected and confirmed COVID-19 patients. In the first part, we add Online COVID-19 Assessment System to provide a self-service COVID19 diagnostic pathway for Hubei's citizens. This system connects with the community health centers and clinics, where the suspected COVID-19 patients are isolated, tested, and diagnosed immediately. This hierarchical medical system can cope with the rapid growth of suspected patients, prevent a collapse of hospitals, and especially avoid secondary transmission in hospitals. In the second part, we add the taxi companies (such as Didi) in the patient transport services (PTS), which are used to substantially reduce PTS activity and the risk of COVID-19 transmission by using public transport. This new form of spontaneous organization volunteers (SVs) can use their established organizations to provide patient transport service with a loose and informal network. In the third part, two artificial intelligent (AI) systems (Artificial Intelligent Triage System and Artificial Intelligent Diagnosis System) are developed and used to improve efficiency in hospitals. Artificial Intelligent Triage System collects and shares the real-time data on local hospitals' current capacity for providing the real-time updates of hospitals' resources available, including the number of suspected, confirmed cases, the number of mild, moderate, and severe cases, mortality and recovery rates, hospital beds, ventilators, and other limited medical resources. This system helps the public health officials balance the load of COVID-19 patients requiring hospitalization across a region and helps patients choose a hospital where they are more likely to be treated quickly. Artificial Intelligent Diagnosis System could improve physicians' diagnostic efficiency. By examining the appearance of COVID-19 in CT lung scans rapidly and accurately (it only takes $10 \mathrm{~s}$ to examine $300 \mathrm{CT}$ lung scans), this system is used to identify the suspected patients within the high-value diagnostic performance. Physicians would further diagnose these suspected patients to timely evaluate whether they may be infected with the COVID-19 virus and whether they need to be treated in isolation. In the fourth part, we add collaborative relationships among various research centers to accelerate the development of diagnostics, vaccines, and therapeutics for COVID-19. Through the database of CDC's Electronic Monitoring System, clinical trials of COVID-19 treatments and interventions are collected from hospitals and clinics, and further exchanged and shared with the research centers to accelerate the development of new drugs for patients hospitalized with COVID-19 and reduce the time taken to set up clinical studies for new therapies. Through the database of Drug and Medical Equipment Information Systems, the latest research results of new drugs, vaccines, and other medical equipments can be shared directly with other research centers by establishing research collaborations. The government officials and public health expert groups control and supervise the research and production processes to ensure the production of safe drugs and medical equipments.

\subsection{Sub-network four: allocating and transporting the funding and medical supplies}

At the peak of the COVID-19 outbreak, the core task of the COVID-19 Collaborative Emergency Network is to allocate funding and transport medical supplies (e.g., personal protective equipment (PPE) and ventilator) quickly and effectively. The sub-network four (shown in Fig. 6) consists of four parts: the first part for providing the funding and medical supplies, the second part for allocating funding and medical supplies, the third part for 


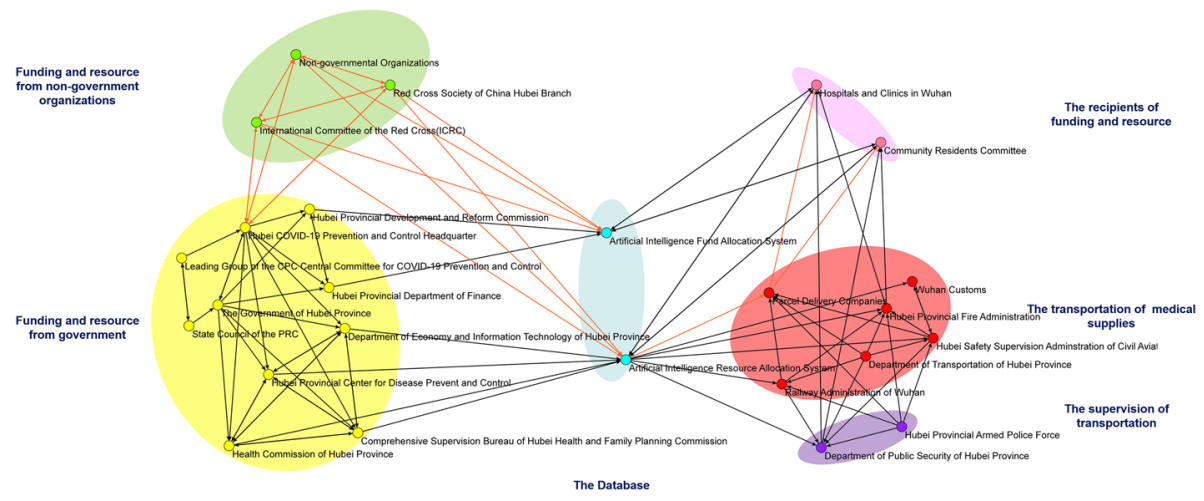

Fig. 6 The framework of sub-network four

transporting the funding and medical supplies, the fourth part for accepting the funding and medical supplies. In the first part, $75 \%$ of the providers are local or central government agencies, and $25 \%$ are non-governmental organizations. Government agencies play a crucial role in providing funding and medical supplies. It ensures the quick and efficient supply of funding and medical supplies because of the Chinese government's strong financial measures. In order to create space for new organizational structures and procedures in this part, we add the collaborative relationships between the government agencies and the nongovernmental organizations. This authorized the collaboration views that "loosening rather than tightening up the command structure (Whittaker et al. 2015) is more effective than the command-and-control-models," and values the autonomy of decision making over the centralization of authority. Non-governmental organizations, as volunteer organizations, have a high degree of flexibility and regulation, which establish the open and fluid structure to ensure and enable autonomy and encourage more supplies and donations from public charities. In Hubei Public Health Emergency Response Network, it is always a challenge for government agencies to match the funding and medical supplies between those who need them and those who can provide them effectively (Shepherd and Williams 2014), and there may be unequal patterns of possessing and delivering funding and medical supplies to the hospitals, clinics, and affected residents. Similarly, the hospitals, clinics, and affected residents may exhibit different patterns of receiving resources so that the resources are delivered to a few neighborhoods more than others. The provision and receipt together is a dynamic setting that shapes the evolution of the demand-driven supply chains. In the second part, we add two artificial intelligence (AI) systems (Artificial Intelligence Fund Allocation System, Artificial Intelligence Resource Allocation System) to allocate funding and medical supplies. These artificial intelligence (AI) systems, combined with the social communication network, are used to inform how funding and medical supplies are allocated and where they come. They build collaborative relationships among the government agencies, the medical equipment, medical supply manufacturers, hospitals, and clinics to share the real-time data on supply and demand. Instead of being predefined, the funding and medical supplies are filled by what the providers do in spontaneously creating operating domains. The flow of funding and medical supplies can also change dynamically according to the recipients' situation. So these two systems are effective channels of distribution that avoid shortages of funding and certain medical supplies in certain hospitals and clinics. To solve the supply-demand imbalance effectively and accurately, social communication 
networks figure prominently in allocating funding and medical supplies. Because communication enacted between providers and recipients is integral to represent the interaction between these two actors. In Hubei Public Health Emergency Response Network, the Red Cross Society of China Hubei Branch is responsible for transporting the medical supplies, relying only on spontaneous and self-organized volunteering programs. These impulsive and unplanned types of volunteering projects reduce the transport frequency and efficiency of medical supplies. So in the third and fourth parts, we add parcel delivery companies to increasing the transport frequency and efficiency by using their preexisting transportation network. Compared with volunteering programs, these companies have a stable connection with the medical equipment and medical supply manufacturers, hospitals, and clinics before the COVID-19 outbreak. For specific transport tasks, the automatic real-time delivery tracking software ensures the government agencies track, manage, and control the allocation of medical supplies. It also helps the public supervise and track the flow of funding and medical supplies donated, which dramatically enhances the transparency and trust in charities.

\subsection{Sub-network five: releasing and publishing the information on COVID-19}

An essential aspect of COVID-19 emergency preparedness and response processes is to release and publish the related information publicly, transparently, timely, and truthfully. The sub-network five (shown in Fig. 7) consists of four parts: the first part for collecting the information on COVID-19, the second part for providing the information on COVID19, the third part for releasing the information on COVID-19, the fourth part for receiving the information on COVID-19. In the first part, it is a significant challenge for the participating actors to get updated information in a highly complex and uncertain environment. During COVID-19 emergency response, there are multiple types of information being sought and exchanged increasingly, and different types of information lend themselves to different exchange media. So the information the actors need is diverse, unpredictable, and continuously changing concerning scope, urgency, and information type (Comfort and Kapucu 2006). By adding five databases in this part, we help the participating actors gather a wide variety of real-time information on COVID-19. Truthfully and timely information

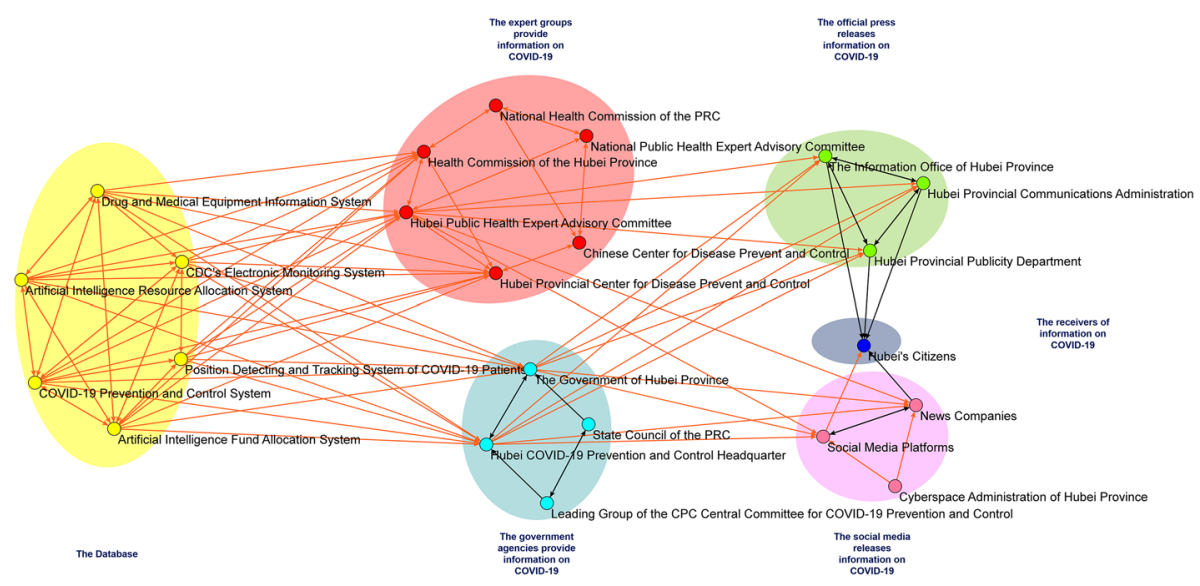

Fig. 7 The framework of sub-network five 
disclosure fulfills the public-serving duties of government organizations, which is most expected by the public in COVID-19 emergency response. This instructing information takes the form of real-time COVID-19 updates, treatment reports, official technical guidance on COVID-19, and so on (Houston 2015). Identifying trusted actors to provide these instructing information on COVID-19 is vital to facilitate the implementation of the COVID-19 emergency response and improve public health emergency preparedness. In this part, we add expert groups to frame prominent public figures, such as Zhong Nanshan, a prominent Chinese expert in respiratory diseases and a hero of the 2003 fight against SARS. These public health experts play essential roles in emergency management, and they often act as "spokesperson" to attract public attention and gain public trust due to their historical experience from SARS. The frequent mentions of public health experts create a sense of openness and personalness on behalf of government organizations, which can be primarily instrumental in strengthening leadership, building trust, and gaining public cooperation (Bruning 2000). Government organizations are expected to provide the necessary information and exhibit more frequent and transparent public communication (Coombs and Holladay 2010). In the preparedness stage, the communication is characterized entirely by information instruction, where issues emphasized included delivering warning information, and preventive measures the public should take. In the response stage, the communication shifts from information delivery to more effective resource mobilization, such as requesting assistance, calling for volunteers and donations, and reporting real-time response updates. The strategy of instructing information is still widely present at this stage, but its emphasis shifts from informing and mobilizing. Therefore, during COVID-19 emergency response, the first source of notification for many (if not most) individuals is information diffused through existing social ties and familiar modes of communication. Thus, people tend to trust and act on information that comes from such ties and communication (Steelman et al. 2014). In the third and fourth parts, compared with the established official press, the social media is added as the new actors to release emergency warnings, notifications, and other critical information to the public. Social media, as the informal communication channel, is often the primary means by which time-sensitive information reaches the public. This capacity of informal communication has been further transformed by the widespread adoption of mobile devices (such as smartphones) and social media technologies (e.g., such as Sina Weibo and Tencent Wechat in China). Meanwhile, social media is often the cause of a great deal of misinformation, and many rumors may spread widely and quickly on social media. The Cyberspace Administration of Hubei Province is added to detect and refute the false rumors, which prevents the spread of rumors and fake news, thus stopping the epidemic of fear and panic.

\subsection{Sub-network six: implementing the training measures and psychological interventions to the public}

During the recovery phase, the training measures and psychological interventions are more effective in being deployed to facilitate the coping of psychological stress and threat. The sub-network six (shown in Fig. 8) consists of four parts: the first part for data sources, the second part for suggesting the training measures and psychological interventions, the third part for deciding the training measures and psychological interventions, and the fourth part for implementing the training measures and psychological interventions. In the traditional training and psychological intervention system, only the 


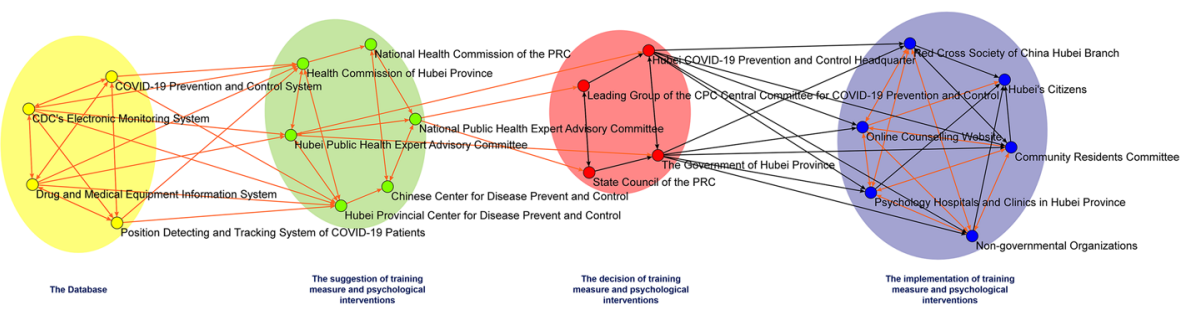

Fig. 8 The framework of sub-network six

government officials create general training measures. It may be impossible to guide local governments to provide personalized training and mental health services. So four databases are added to provide the real-time information of COVID-19, prevention and control measures, and vulnerable in a specific community, which can be used by the local government to identify and implement suitable prevention and control measures to mitigate the risk of COVID-19 infection in their communities, train the local individuals and households to measure and manage their mental health by the counselor and onward support. During the recovery phases, government agencies see their most pressing problems as looking for practical training measures and psychological interventions, demanding the collective expertise of public health experts (Weick and Sutcliffe 2007). So in the second and third parts, these experts are added to "join at the top" (collaborate with government agencies) and "join up at the base" (collaborate with communities), who are at the core position to provide professional support for developing these measures (Christensen and Lægreid 2007). Public health experts frequently plan and practice training exercises for different kinds of incidents with emergency medical units. By shifting the isolated expert system into a cross-sector collaborative system, the subgroup of experts can be used to develop cross-disciplinary relationships and work out integrated training measures and psychological interventions to the public. In the fourth part, we propose "Strengthening Community Network," which is considered as an essential way of building "community response capacity to COVID-19" (Chaskin et al. 2001). This part highlights the importance of involving local emergency management organizations, including non-profits and local communities. The implementation of training measures and psychological interventions needs to consider the preexisting community connections and civil and grassroots relationships in communities. Meanwhile, the flexible social mobilization of non-governmental organizations helps the government agencies use the "smile" force to implement the training measures and psychological interventions. So it ensures that these measures can be fully understood and actively participated by the local individuals and households. The training measures and psychological interventions implemented locally during the preparedness phase can help strengthen existing friendships and develop new formal ties among local individuals and households. The individuals and households in this close-knit and tight network exhibit the lowest access to support from outside the group and provide built-in flexibility for communicating. Online Counseling System is added to provide online communication between local individuals, households, and healthcare workers. This social networking service is an online platform to collect and summarize the messages of many people who want help. These messages are used by psychological experts, healthcare workers, 
and volunteers to provide practical and emotional support through this informal communication network.

\subsection{Network analysis of comparison for Hubei Public Health Emergency Response Network and COVID-19 Collaborative Emergency Network}

In COVID-19 Collaborative Emergency Network, inter-organizational collaboration among the participating actors is highly complex. Compared with the actual network, an increased number of the participating actors and increased collaborative ties in the planned network are required to complete six core tasks. Based on our network analysis using the Pajek software, Table 1 compares these two networks with descriptive statistics. In total, 72 participating actors in COVID-19 Collaborative Emergency Network are compared with 62 participating actors in Hubei Public Health Emergency Response Network, with a large proportion of governments (37 actors). The majority of the government agencies are provincial governments (28 actors), which handle the COVID-19 emergency response activities domestically, directly, and quickly. It is noteworthy that the number of participating actors has increased significantly in databases and AI Systems (12 actors in COVID-19 Collaborative Emergency Network, only four in Hubei Public Health Emergency Response Network). These newly added AI Systems are used to collect, store, and transfer the realtime information on COVID-19 to the participating actors timely, which ensure the implementation of the critical preparedness, readiness, and response actions for COVID-19. Lastly, given the relatively low proportion of non-profit organizations (four actors) and private organizations (five actors) involved in the COVID-19 Collaborative Emergency Network, this implies that the government agencies play the central role in response to COVID-19 due to China's one-party system. Accordingly, the number and strength of ties describe the depth and complexity of inter-organizational relationships among the participating actors. Compared with Hubei Public Health Emergency Response Network, all types of participating actors have significantly increased number and strength of ties in COVID19 Collaborative Emergency Network, especially in non-profit organizations and research institutions (more than five times), databases and AI Systems (more than 10 times). Moreover, the average number of relationships (including collaborative relationships, reporting or governance relationships) among all types of actors is also increased significantly. The non-profit organizations (from 0 to 4.25) and research institutions (from 0 to 5.57) are supposed to build a large number of new collaborative relationships with other types of participating actors in COVID-19 Collaborative Emergency Network. Hence, these newly increased and strong collaborative relationships demonstrate that in COVID-19 Collaborative Emergency Network, the collaborating response to COVID-19 is extraordinarily more effective than that in Hubei Public Health Emergency Response Network.

The network analysis of COVID-19 Collaborative Emergency Network emphasizes the role that whole network structural characteristic played in predicting the formation of collaborative relationships (shown in Table 2). Compared with Hubei Public Health Emergency Response Network, COVID-19 Collaborative Emergency Network involved more actors (72 actors) actively collaborating in COVID-19 emergency response. No actors (0\%) were isolated from others, meaning that actors were able to build and maintain more direct collaborative interaction with others than that in Hubei Public Health Emergency Response Network. Accordingly, COVID-19 Collaborative Emergency Network has a higher density than Hubei Public Health Emergency Response Network, which implies the denser relationships with multiple support sources to produce a more connected network. The 


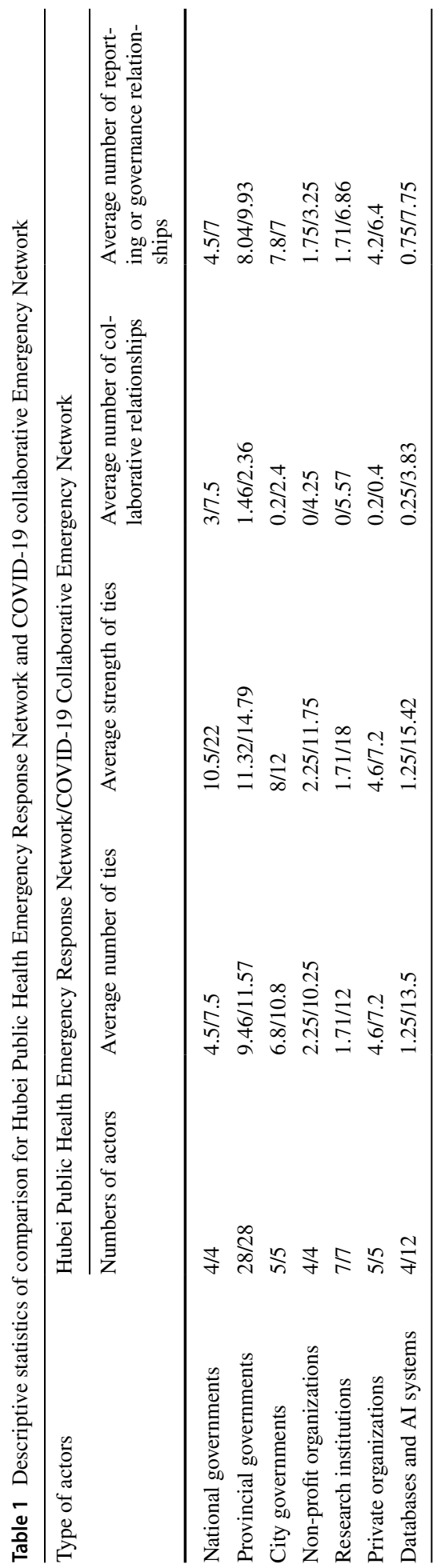




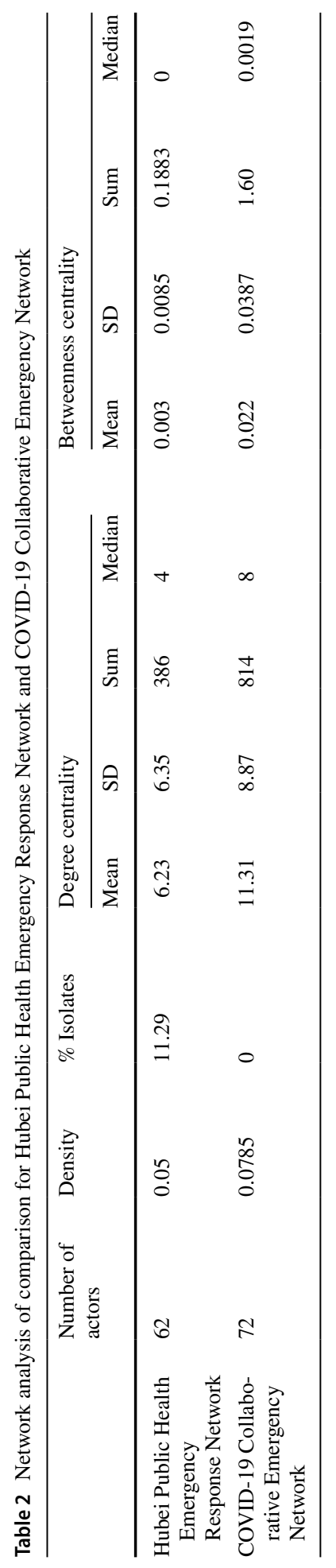


network degree centrality score and variance of COVID-19 Collaborative Emergency Network are higher than that of Hubei Public Health Emergency Response Network, which leads to the conclusion that there is a large amount of concentration or centralization in the former network. Moreover, these direct connections mean overall positional advantages of some participating actors in collaborating COVID-19 emergency response activities. Both networks have a low level of betweenness centrality. Such a situation might be especially favorable because of the nature of the emergency response, which characterizes less rigid structures and relationships and more flexible operations on scene. The results produce reliable evidence to indicate that COVID-19 Collaborative Emergency Network has a more tightly, connective, and central structure than the Hubei Public Health Emergency Response Network, which has a significant favorable influence in improving the performance and behavior of inter-organizational collaboration in response to COVID-19 outbreak in Hubei Province.

To more precisely verify these findings, the network analysis of each participating actor in these two networks was explored. Table 3 shows a set of participating actors with the highest rank scores. (1) According to degree centrality analysis, most of participating actors (90\% in Hubei Public Health Emergency Response Network and 50\% in COVID-19 Collaborative Emergency Network) with high scores are provincial governments, which indicates that the formal connections may be centered on provincial governments. Notably, the Government of Hubei Province has the highest score in both two networks, followed by Hubei COVID-19 Prevention and Control Headquarters. As the direct commander and organizer of the implementation of COVID-19 emergency response activities in Hubei Province, these actors are considered to be the center of these two networks. Meanwhile, compared with Hubei Public Health Emergency Response Network, the participating actors that have more ties with others have higher degree centrality in COVID-19 Collaborative Emergency Network, which indicates that these actors are more embedded and central and dominant. There are significant differences between these two networks that five actors of the top ten actors are Databases and AI Systems in COVID-19 Collaborative Emergency Network. These databases and systems are added to help the actors gather a wide variety of real-time information on COVID-19, which fills the gaps in communication and interactions among actors to acquire data and transfer information timely and directly. (2) According to the betweenness centrality analysis, all of the top-ranked actors have low scores in both networks. It should be pointed out that the participating actors in both networks are not very dependent on single specific actors to collaborate with others. (3) According to structural hole analysis, there are more structural holes existed in Hubei Public Health Emergency Response Networks. In this network, seven of the top ten ranked actors (e.g., International Committee of the Red Cross(ICRC), Cyberspace Administration of Hubei Province, Wuhan's Citizens, etc.) were isolated from other actors, meaning that they were not able to build and maintain direct collaborative relationships with other actors. The other top-ranked actors (e.g., Wuhan Center for Disease Prevent and Control(CDC), World Health Organization(WHO), Hospitals and Clinics in Hubei Province) connected with the network only depends on a single actor. It is worth demonstrating that the major of the top-ranked actors are research institutions and non-profit organizations, who may face severe problems of isolation that challenge their access to provide professional suggestions to policymakers and the public, and new forms of self-organized volunteering programs. These structural holes or unconnected actors should be identified to create ties for possible collaborative opportunities. Filling these structural holes by local agencies, it can proactively strengthen the collaborative capacity of the network. Therefore, in COVID-19 Collaborative Emergency Network, a large number of ties have been embedded in the network 


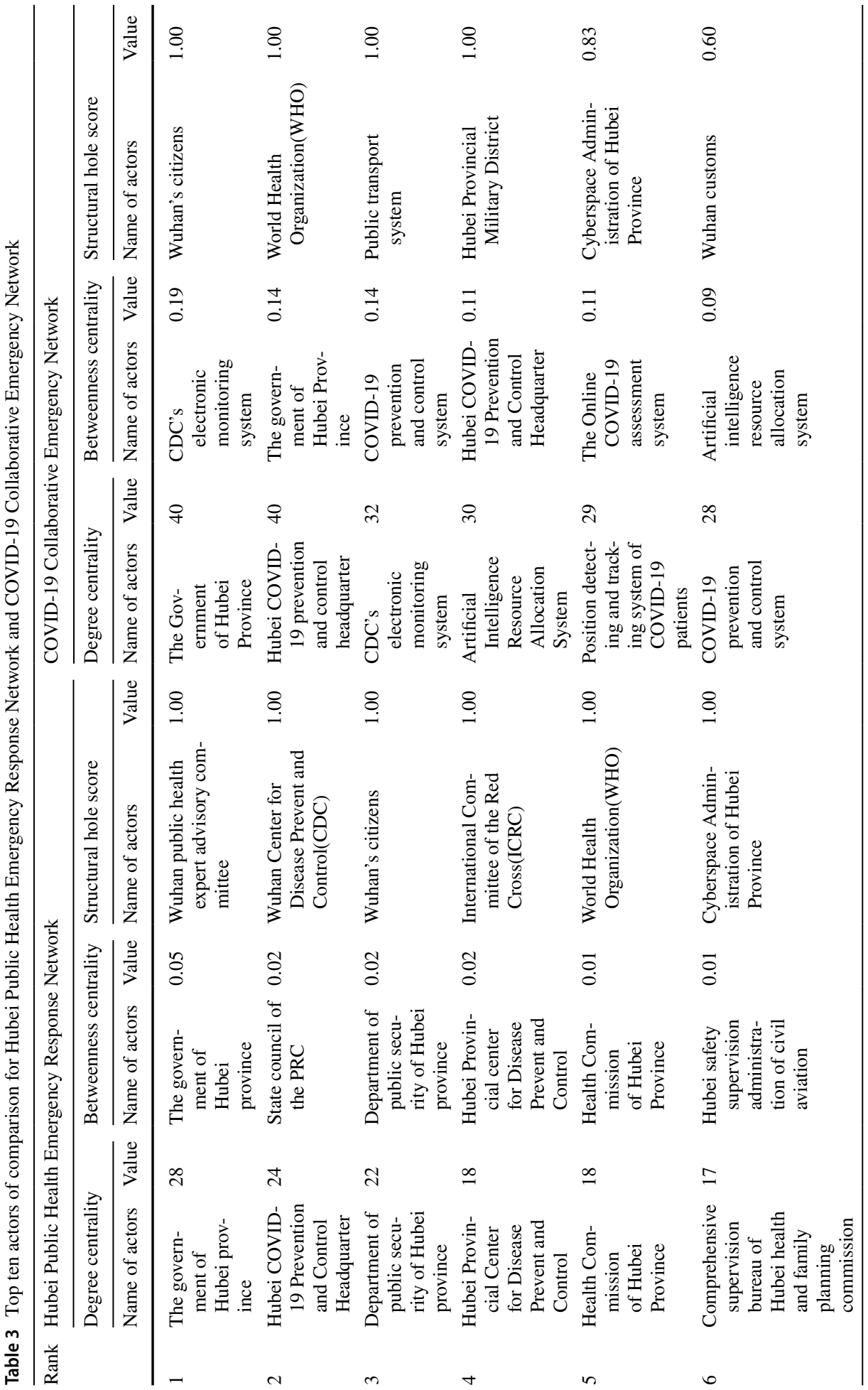




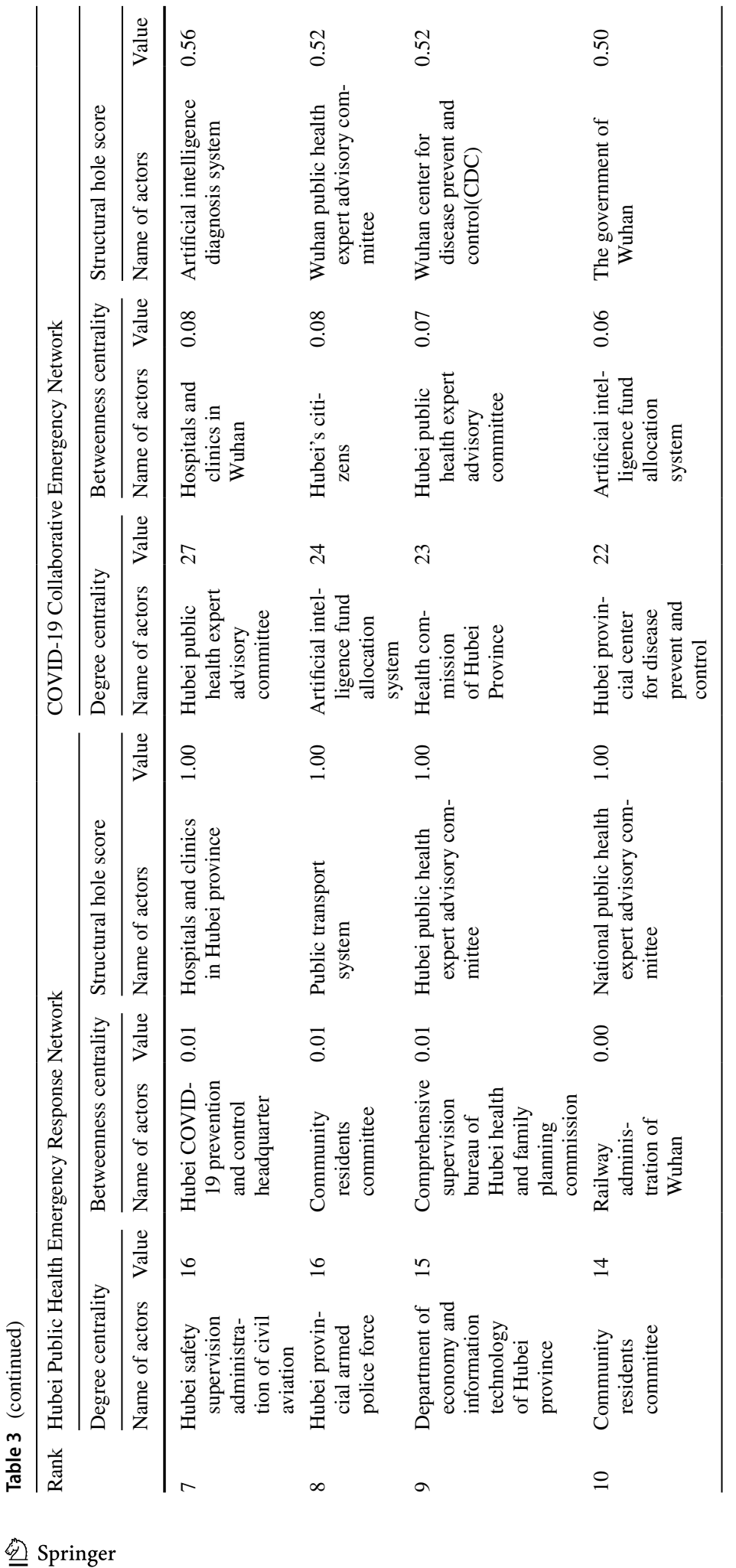


structure to make the connections with the isolated actors and reduce the structural holes. Only four of the top ten ranked actors connected with the network depends on a single actor. These actors (e.g., Wuhan Municipal Health Commission, National Health Commission of PRC), who bridge structural holes, may be considered to be brokers and often occupy considerable influence. Public's Electronic Reporting System and Online COVID19 Assessment System, who played brokerage roles, are AI Systems. These two brokers can provide information and resources to the structural holes timely and accurately.

\subsection{Network analysis of comparison for six sub-networks of COVID-19 Collaborative Emergency Network}

In the COVID-19 Collaborative Emergency Network, the different participating actors and their different collaborative relationships form six sub-networks to accomplish six core tasks in response to COVID-19, which also produce the different structural characteristics of these sub-networks. Pajek software was used to provide a comprehensive picture of the different inter-organizational relationships in each sub-network (shown in Table 4). Subnetwork three involved the most number of actors for treating the patients and researching the COVID-19. Even though differences appear to be small, density appears to be in favor of sub-network five and six in all six sub-networks. The denser relationships produce the more connected sub-networks. This situation is especially preferable when multiple support information is essential for releasing and publishing the information on COVID-19 in sub-network five. During the recovery phase, when community psychological interventions are redundancy, it is essential as an alternative to possible disruptions. The sub-network six with denser relationships between public health experts and government provides professional supports to develop training measures. Sub-network five has the highest degree of centrality score and variation. Its degree centrality score is 1.8 times that of sub-network one. The overall betweenness centrality of all sub-networks is relatively low, and the differences are comparatively small. Regardless of the structure, there is a relatively low amount of "power" in these sub-networks, which results in little inequality in terms of a certain actors' brokerage role. It means that there are many alternatives for actors in collaborating with others, without being dependent on single actors.

The network analysis of each participating actor in six sub-networks is used to test and increase our confidence in the most relevant actors in complementing different tasks. We preselected the top five actors with the highest rank and score in each sub-network (shown in Table 5). (1) Degree centrality measures the total connections an actor has in each subnetwork, which can be used to identify actors with an extensive collaborative activity. In six sub-networks, due to the different core tasks, there are significant differences in top-ranked actors. For example, for monitoring, early warning, and reporting the COVID-19, Wuhan Municipal Health Commission, Hospitals, and Clinics in Wuhan and other city governments with high degree centrality scores were the most critical ones in sub-network one. These actors who had more connections or communications with other actors had more significant opportunities to understand the new transmission dynamics of the infection and report the latest epidemic situation of the COVID-19 in Wuhan timely and accurately. To treat the patients and research the COVID-19, Hubei Public Health Expert Advisory Committee, Research Centers, and other research institutions with highly degree centrality scores were the most active ones in sub-network three. These actors directly collaborated to provide scientific and reasonable suggestions for optimizing COVID-19 prevention and control measures. In sub-network five, CDC's Electronic Monitoring System and other 


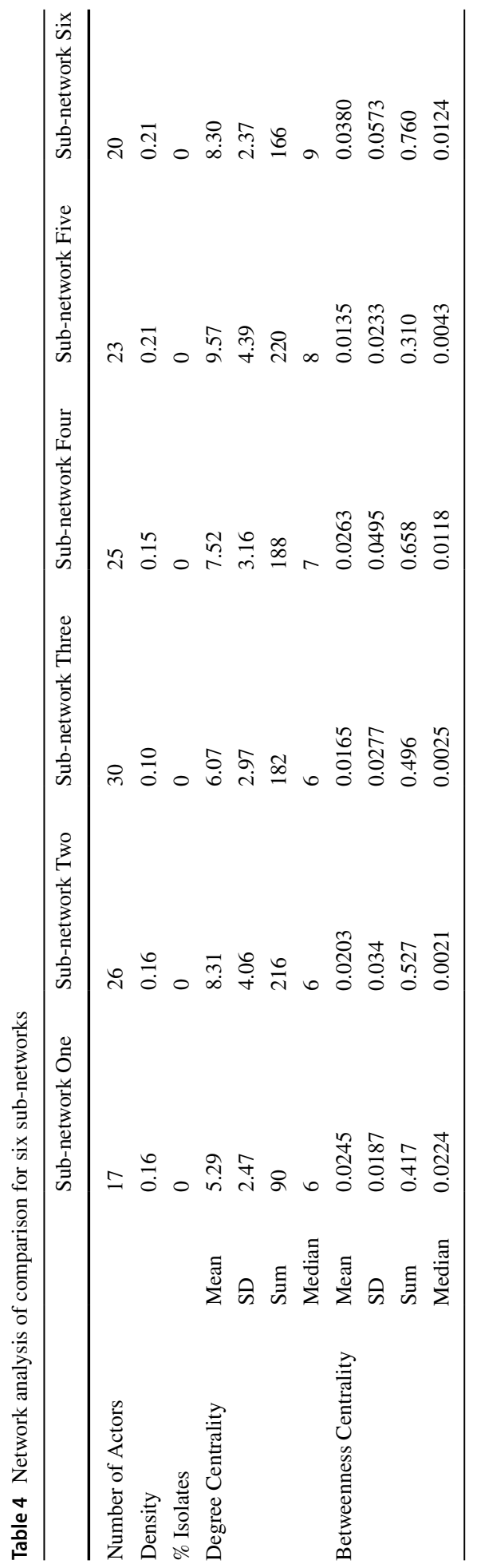




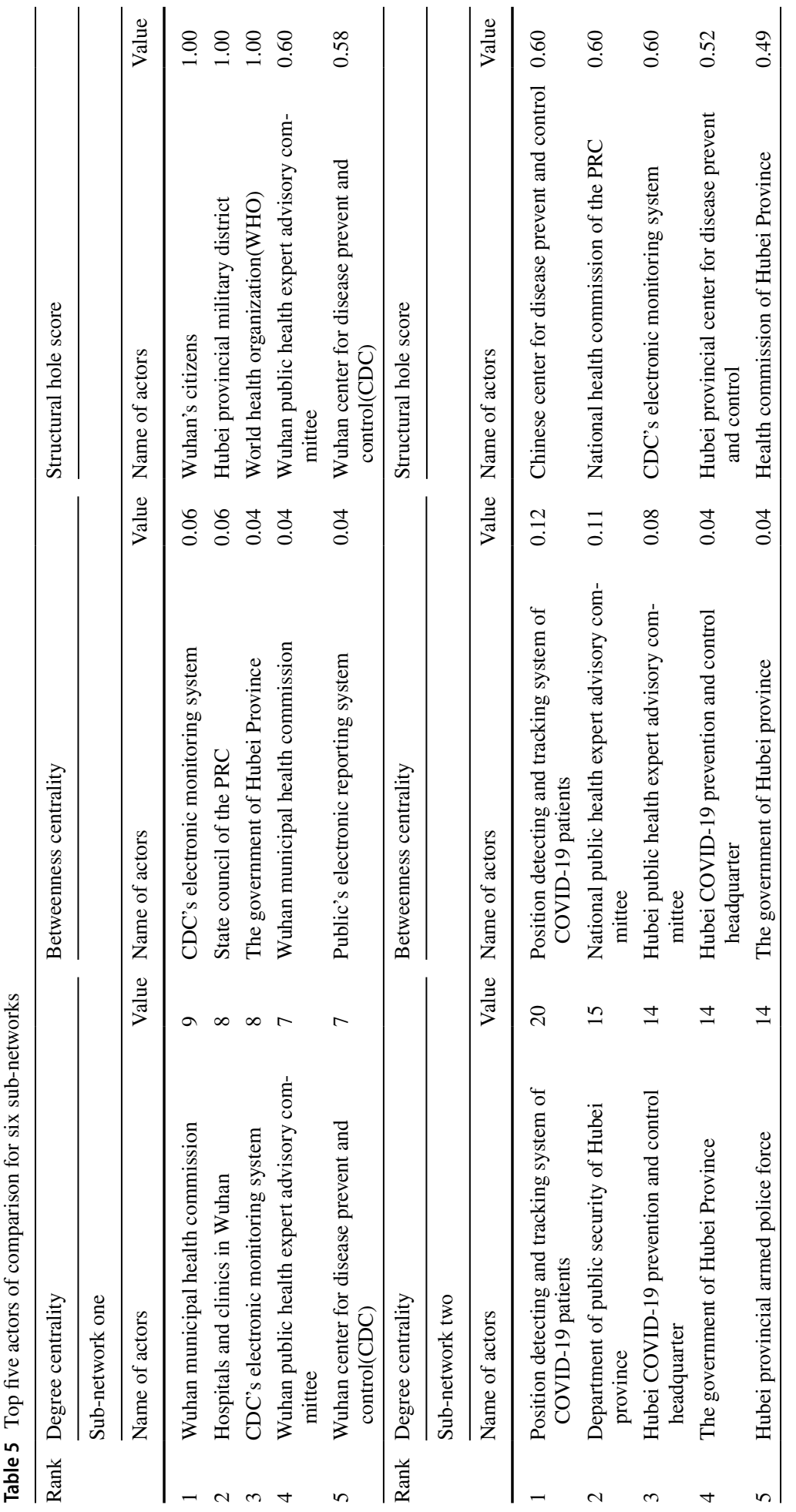




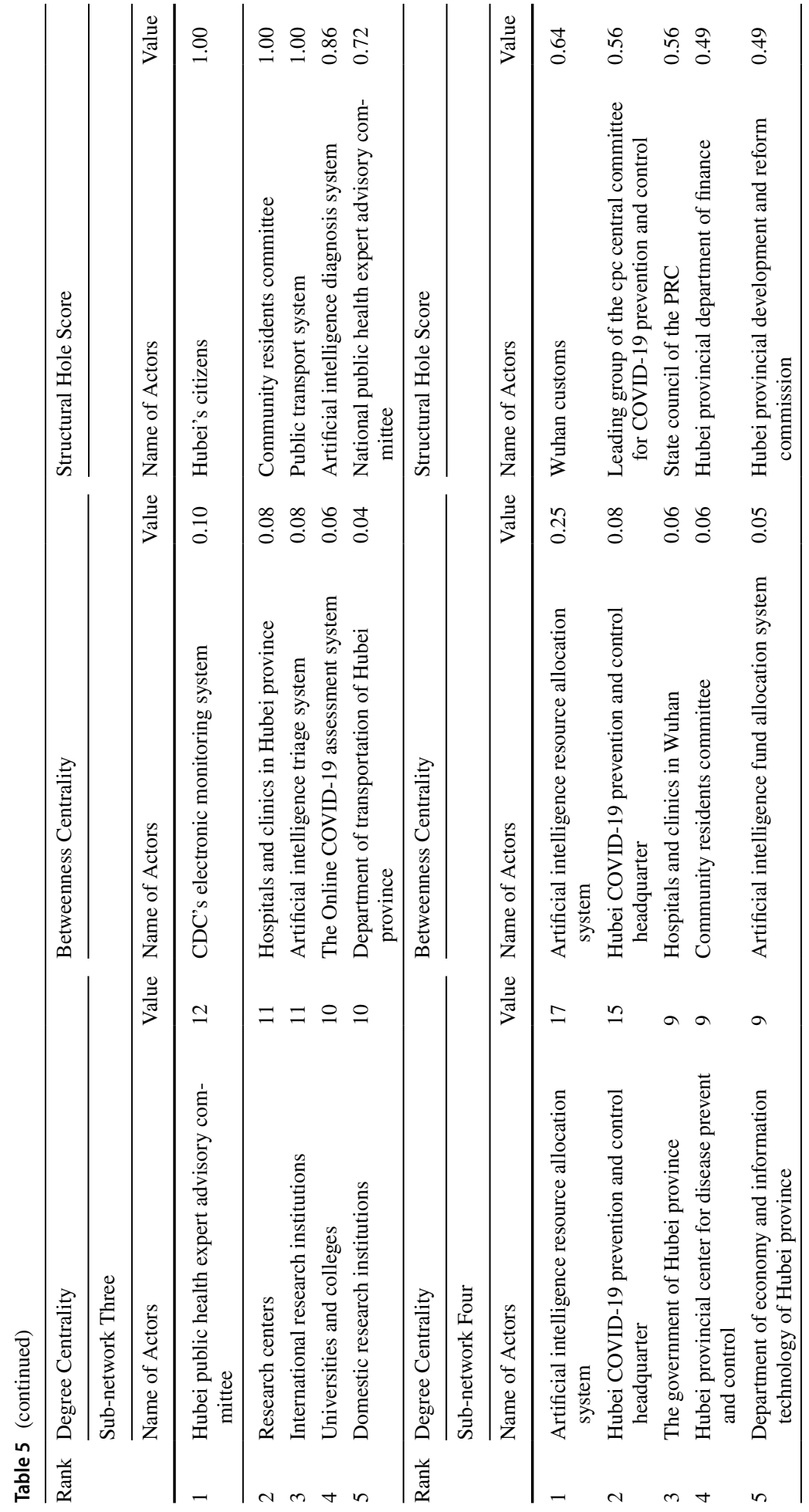




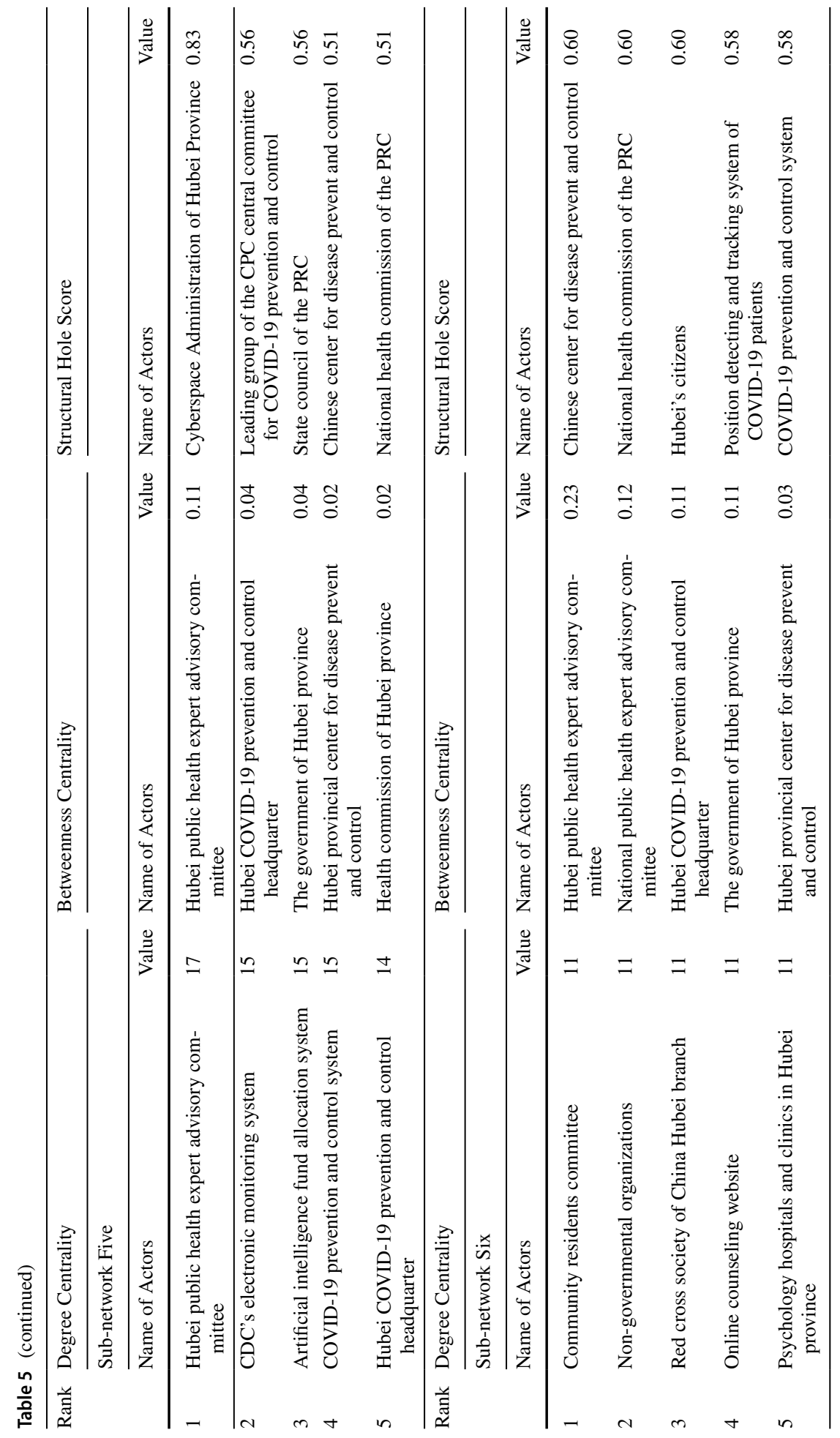


AI Systems with high degree centrality scores represented a crucial role in accomplishing their duties to update the real-time information on COVID-19 to health pubic experts and policymakers. By connecting with more actors, these systems hence were more potent in improving the cohesiveness of sub-network five. (2) Betweenness centrality considers the number of paths in each sub-network that pass through a particular actor and therefore measures the dependence of a sub-network on a particular actor for maintaining collaboration. Most of the top-ranked actors in these six sub-networks had relatively low scores, and there is not a significant gap. However, Artificial Intelligence Resource Allocation System (marked by yellow color) has a higher score than other actors in sub-network four, followed by Hubei Public Health Expert Advisory Committee (marked by yellow color) in sub-network six. In sub-network four, by building the connection with the government agencies, the medical equipment, and medical supply manufacturers, hospitals, and clinics, Artificial Intelligence Resource Allocation System directly filled the supply-demand gaps to allocated medical supplies effectively and accurately. In sub-network six, Hubei Public Health Expert Advisory Committee first connected with CDC's Electronic Monitoring System and Drug and Medical Equipment Information System to get the data sources of the transmission and clinical characteristics of COVID-19, and the real-time research and production of new drug and medical equipment. Then it collaborated with The Government of Hubei Province and Hubei COVID-19 Prevention and Control Headquarter to provide professional support for work out integrated training measures and psychological interventions. These two actors with the highest scores indeed occupied a uniquely prominent position in sub-network four and six separately. (3) Structural hole analysis is used to identify where collaborative relationships have failed to form in six sub-networks, and whether the actors in these sub-networks lack reliable and stable collaborative relationships. Due to the lower structural hole scores of the top-ranked actors, no significant structural hole existed in subnetwork two, four, five, six. However, Wuhan's Citizens, Hubei Provincial Military District, World Health Organization (WHO) (marked by green color) in sub-network one, and Hubei’s Citizens, Community Residents Committee, Public Transport System (marked by green color) in sub-network three had the highest scores. Moreover, State Council of the PRC, Wuhan Municipal Health Commission, Public's Electronic Reporting System in subnetwork one, Online COVID-19 Assessment System in sub-network three played several brokerage roles. These actors highly depended on a single broker separately to connect with the sub-networks. However, these connections were the reporting relationships (represented by a single-headed arrow), that the actors who played the role of brokers, just sent or received the real-time data and information, which suggested that these "structural holes" did not result in uncertainty, unreliable and unstable interactions in sub-network one and three.

\section{Discussion and conclusion}

The COVID-19 outbreak is a global problem, an unprecedented pandemic, a public health emergency of international concern that threatens the lives and well-being of the world population. It requires a global solution. Global collaboration is the engine for solving this problem. It is thus crucial for sharing available data to address how different governments respond differently to this crisis around the world, how to strengthen best government's capacity for preventing, responding to, and ending this pandemic, how to provide better support to health workers or professionals, and what are effective interventions to 
protest the vulnerable. These open sources bring together the best minds, policies, practices from different countries for the benefit of all. China is the first country to respond to the COVID-19 outbreak, and $81.5 \%$ of the confirmed cases are concentrated in Hubei province (updated to 8th April 2020). At the early stage of the COVID-19 outbreak, the integrated non-pharmaceutical interventions deployed in Hubei province proved to achieve the most reliable and most rapid effect, which would likely result in a 67-fold reduction of the number of COVID-19 cases (Lai et al. 2020). Therefore, the case study of the COVID19 outbreak in Hubei provides us with an essential scientific window into forming a collaborative network for implementing these non-pharmaceutical interventions. This study revealed how the participating actors mobilized and collaborated their response activities by presenting the framework of Hubei Public Health Emergency Response Network. Then, the network analysis examined the structure and performance of this actual network, which identified the types and proportion of different participating actors, implied the strong relationships among some actors, highlighted the actors who were isolated, who were the structural holes, and who played the central, bridge or brokerage roles. By perceiving, experiencing, and learning the significance of these special actors and their unique relationships through COVID-19, this study proposed a new collaborative network (COVID19 Collaborative Emergency Network) to optimize the actual network's performance and capacity by adding new actors, establishing new ties, and maintaining existing ties as procedures of the network evolution.

The findings provide two contributions: First, this study presented the overall framework of COVID-19 Collaborative Emergency Network and used network analysis to quantify and distinguish the structure and performance of this planned network in comparison to the actual network. At the network level, the network analysis presented that COVID19 Collaborative Emergency Network was the relatively higher density and more centrality, especially in terms of more actors and no isolated actors, more powerful and strong relationships, and a higher number of data sources. Since emergency management is more about timely decision-making than implementation, these decisions during the COVID-19 response relied heavily on accurate and timely information. In the actual network, information dependency is a threat to the actors with few or no relationships. What is more, the highly central actors may also become dysfunctional in time-sensitive emergencies. In this planned network, the majority of the newly added actors are Databases and AI Systems. The different Databases and AI Systems were added in different sub-networks for 'automatically' providing real-time information on the transmission and clinical characteristics of COVID-19, the trace of the suspected cases and close contacts, the implementation of prevention and control measures in different regions, the research and production of new drug and medical equipment, and the allocation of funding and medical supplies. Compared with the formal communication ties, these Databases and AI Systems as nonhierarchical, are more viable in the face of ever-changing and worsening COVID-19 crisis. Accordingly, in the actual network, more than $50 \%$ of the isolated actors were nonprofit organizations and research institutions, and there were no collaborative relationships among these actors. Thus, the limited relationship involvement was generally a barrier to the engagement and influence of these actors, which might negatively impact the network's emergency response capability by not allowing professionals to execute on behalf of the network. In the planned network, stronger connections and meaningful collaborative relationships were created for non-profit organizations and research institutions. Having the network connected more with non-profit organizations encourages more broad participating actors, which reduces the uncertainty and relational risk from just relying on the local governments' behaviors. The stronger collaborative relationships between government 
agencies and research Institutions potentially make the policymakers hear from public health experts directly, and knowledge sharing, when the effective and timely sharing and transferring of the expert knowledge and skills are quite important in the time-sensitive and resource-dependent field of emergency management. The newly added strengthening of collaborative relationships among different research institutions provided opportunities to combine cutting-edge scientific capabilities with specific local contexts, making the benefits of research available to develop diagnostics, vaccines, and treatments to tackle health emergencies. At the node level, this study applied network analysis to explore which actors acted as central roles, key bridges, or brokers in Hubei Public Health Emergency Response Network and COVID-19 Collaborative Emergency Network separately to assess the conditions critical for utilizing effective collaboration networks. One should note that most of the central actors in both networks were provincial governments, which demonstrated that the implementation of COVID-19 emergency response activities relied heavily on local collaborative initiatives rather than national initiatives in Hubei Province. Moreover, the higher degree centrality of Databases and AI Systems in the COVID-19 Collaborative Emergency Network meant that these actors had more connections with other actors, who played the important roles of sharing real-time information, resources, and skills gained from different levels of response activities. Besides, there were more structural holes in Hubei Public Health Emergency Response Network. The majority of these holes were research institutions and non-profit organizations, which were isolated and had no or just a single connection with the network. By drawing on the structural effects as a mechanism for collaboration, in COVID-19 Collaborative Emergency Network, local agencies used to fill these structural holes, played key brokerage roles to reduce uncertainties associated with network building problems. Consequently, when requiring up-to-date professional knowledge to support the continuous decision-making, local agencies could 'bridge' the collaboration between authorities and research institutions, which positively created strong relationships with public health experts as the full-time advisers. In terms of seeking more assistance to implement COVID-19 response activities, local agencies could be activated to improve collaborative opportunities with non-profit organizations.

Second, this study suggested that a focus on the task-oriented collaborative network can help, not hinder, the achievement of commonly desired tasks such as more actors, more and stronger relationships among actors. By building six sub-networks to define six core tasks in response to COVID-19, it is predicated on the principals that all the participating actors and relationships involved in each sub-network are essential to accomplishing each core task (e.g., monitoring, early warning and reporting the COVID-19, implementing COVID19 prevention and control measures, treating the patients and researching the COVID-19, allocating and transporting the funding and medical supplies, releasing and publishing the information on COVID-19, and implementing the training measures and psychological interventions to the public). This is in the success of dealing with the dilemmas include: (1) which actors should be involved in each sub-network, (2) with whom an actor should create relationships, (3) whether to forge a relationship as a collaboration, reporting or governance. At the network level, sub-network three was characterized by the most desired actors, which seemed to fit better for treating the patients and researching the COVID-19. Rely on more multiple relationships, sub-network five appeared to be more centrality and higher density, and the strengthening of its structure is essential to release and publish the information on COVID-19, which is desirable in the context of emergency management. The six sub-networks combined with low betweenness centrality all had the more egalitarian and dense networks that would minimize the power of some specific actors. As more connections in terms of network relationships meant more degree centrality at the node level, 
this study identified that the key actors in each sub-network were different, which is essential to accomplish different core tasks. For example, the Wuhan Municipal Health Commission and Hospitals and Clinics in Wuhan were the central actors for monitoring, early warning, and reporting the COVID-19 in sub-network one. Hubei Public Health Expert Advisory Committee and Research Centers played the central roles in treating the patients and researching the COVID-19 in sub-network three. Most of the participating actors in six sub-networks had the relatively low betweenness centrality, except Artificial Intelligence Resource Allocation System in sub-network four, and Hubei Public Health Expert Advisory Committee in sub-network six. These two actors had shorter paths to other actors, which held the more critical positions in the sub-network. Viewed the structural holes, sub-network two, four, five, and six did not have any significant structural hole. However, it should be noted that Wuhan's Citizens, Hubei Provincial Military District, and World Health Organization (WHO) in sub-network one, Hubei's Citizens, Community Residents Committee, and Public Transport System in sub-network three had the highest structural hole scores. These actors, as the structural holes, only loosely connected with the sub-networks by a single actor, which might face severe problems of isolation that challenged their access to critical information and resources. However, the reporting relationships, not collaborative relationships among these actors, made the structural holes just need to send or receive the real-time data and information. Thus, the reduced connection involvement had a limited influence on the sub-network performance.

The findings in this study are considered consistent with the argument provided by Lee (2017), who strongly underscored the point that the sparse collaborative network relied heavily on emergency planning, was always a paper-based system. In Hubei Province, Hubei Public Health Emergency Response Network was built based on the Hubei Public Health Emergency Response Plan. Due to unclear tasks and uncertain partners, the interorganizational collaborations in this network sometimes failed in providing the resources and critical information needed by local participating actors during the COVID-19 emergency response. It emphasizes the necessity of task-oriented collaboration, as confirmed by this study. However, this study is not without limitations. First, a single dataset was used to examine a case of COVID-19 outbreak in Hubei Province, China. Future study should replicate this COVID-19 Collaborative Emergency Network at local, regional, and national levels of other regions and countries to increase the generalizability of the conclusions. Second, in-depth interviews with different types of actors, especially local organizations, could provide more data points (and sources), which validates future research. Third, this study is limited to the COVID-19 emergency response and can be applied in any other public health emergency management field in which collaboration is needed.

Acknowledgements This research was supported by National Social Science Foundation of China (No. 20CGL051).

\section{Compliance with ethical standards}

Conflict of interest The authors declare that they have no conflict of interest.

\section{References}

Bouckaert G, Peters GB, Verhoest K (2010) The coordination of public sector organizations: shifting patterns of public management. Palgrave Macmillan, Basingstoke 
Bruning SD (2000) Examining the role that personal, professional, and community relationships play in respondent relationship recognition and intended behavior. Commun Q 48(4):437-448

Bryson JM, Crosby BC, Stone MM (2006) The design and implementation of cross-sector collaborations: propositions from the literature. Spec issue, Pub Adm Rev 66:44-55

Chaskin RJ (2001) Building community capacity: a definitional framework and case studies from a comprehensive community initiative. Urban Aff Rev 36(3):291-323

Choi SO, Brower RS (2006) When practice matters more than government plans: a network analysis of local emergency management. AdmSoc 37(6):651-658

Comfort LK (2007) Crisis management in hindsight: cognition, communication, coordination, and control. Pub Adm Rev 67(1):189-197

Comfort LK, Waugh WL, Cigler BA (2012) Emergency management research and practice in public administration: emergency, evolution, expansion, and future directions. Pub Adm Rev 72:539-547

Coombs WT, Holladay SJ (2010) The handbook of crisis communication. Wiley-Blackwell, Malden, MA

Feiock RC, Lee WI, Park HJ (2012) Administrators' and elected officials' collaboration networks: selecting partners to reduce risk in economic development. Pub Adm Rev 72(1):58-68

Ferlie E, Pettigrew A (1996) Managing through networks-some issues and implications for the NHS. Br J Manag 7:81-99

Hill CJ, Lynn LE (2009) Public management: a three dimensional approach. Congressional Quarterly Press, Washington

Houston JB (2015) Bouncing forward: assessing advances in community resilience assessment, intervention, and theory to guide future work. Am Behav Sci 59:175-180

Huxham C, Vangen S (2005) Managing to collaborate: the theoryand practice of collaborative advantage. Routledge, London

Isett KR, Mergel IA, LeRoux K, Mischen PA (2011) Networks in public administration scholarship: understanding where we are and where we need to go. J Pub Adm Res Theory 21(s1):i157-i173

Jennings ET, Ewalt AJ (1998) Interorganizational coordination, administrative consolidation and policy performance. Pub Adm Rev 58(5):413-421

Kapucu N (2006) Public-nonprofit partnerships for collective action in dynamic contexts. Pub AdmInt Q $84: 205-220$

Kapucu N, Demiroz F (2011) Measuring performance for collaborative public management using network analysis methods and tools. Pub Perform Manag Rev 34(4):549-579

Kapucu N, Garayev V (2012) Designing, managing, and sustaining functionally collaborative emergency management networks. American Rev Pub Adm 43(3):312-330

Knoke D (1990) Political networks. the structural perspective. Cambridge University Press, Cambridge

Koliba CJ, Meek JW, Zia A, Mills RW (2010) Governance networks in public administration and public policy. CRC Press, New York

Lai S, Ruktanonchai NW, Zhou L, Prosper O, Luo W, Floyd JR, Wesolowski A, Santillana M, Zhang C, Du X, Yu H, Tatem AJ (2020) Effect of non-pharmaceutical interventions to contain COVID-19 in China. Nat publ online 585(7825):410-413

Lee B (2017) Urban core infrastructure management before, during, and after a disaster. Plan and Policy 430:5-12

Molenveld A, Verhoest K, Voets J, Steen T (2019) Images of coordination: how implementing organizations perceive coordination arrangements. Pub Adm Rev 80(1):9-22

Noori NS, Wolbers J, Boersma K, Cardona XV (2016) A Dynamic Perspective of Emerging Coordination Clusters in Crisis Response Networks. In Proceedings of the ISCRAM 2016 Conference-Rio de Janeiro, 1-9.

Provan KG, Milward BH (1995) A Preliminary theory of interorganizational network effectiveness. AdmSci Q 40(1):1-33

Provan KG, Lemaire RH (2012) Core concepts and key ideas for understanding public sector organizational networks: using research to inform scholarship and practice. Pub Adm Rev 72:638-648

Provan KG, Fish A, Sydow J (2007) Interorganizational networks at the network level: a review of the empirical literature on whole networks. J Manag 33(3):479-516

Rhodes RAW (1996) The new governance: governing without government. Political Stud 44:652-667

Robinson SE, Eller WS, Gall M, Gerber BJ (2013) The core and periphery of emergency management networks. Pub Manag Rev 15:344-362

Shepherd DA, Williams TA (2014) Local venturing as compassion organizing in the aftermath of a natural disaster: the role of localness and community in reducing suffering. J Manage Stud 51(6):952-994

Steelman TA, Nowell B, Bayoumi D, McCaffrey S (2014) Understanding information exchange during disaster response: methodological insights from infocentric analysis. Adm Soc 46(6):707-743 
Topper CM, Carley KM (1999) A structural perspective on the emergence of network organizations. J Math Sociol 24(1):67-96

Turrini A, Cristofoli D, Frosini F, Nasi G (2010) Networking literature about determinants of network effectiveness. Pub Adm 88(2):528-550

Wasserman S, Faust K (1994) Social network analysis: methods and applications, vol 8. Cambridge University Press, Cambridge, UK

Waugh WL Jr, Streib G (2006) Collaboration and leadership for effective emergency management [special issue]. Pub Adm Rev 66(s1):131-140

Weick KE, Sutcliffe KM (2007) Managing the unexpected: resilient performance in an age of uncertainty, 2nd edn. Jossey-Bass, San Francisco

Whittaker J, McLennan B, Handmer J (2015) A review of informal volunteerism in emergencies and disasters: definition, opportunities and challenges. Int J Disaster Risk Reduction 13:358-368

Wilson L, MacDonald BH (2018) Characterizing bridger organizations and their roles in a coastal resource management network. Ocean Coast Manag 153:59-69

World Health Organization (2020) Coronavirus Disease (COVID-2019) Situation Reports

Publisher's Note Springer Nature remains neutral with regard to jurisdictional claims in published maps and institutional affiliations. 